\title{
Puerperal Pregnancy Psychopathology: The Psychic Space of Unsafe Abortion in a Gabonese Woman
}

\author{
Samuel Mbadinga \\ Departement of Psychology, the Omar Bongo University, Libreville, Gabon \\ Email address: \\ sambading@yahoo.fr

\section{To cite this article:} \\ Samuel Mbadinga. Puerperal Pregnancy Psychopathology: The Psychic Space of Unsafe Abortion in a Gabonese Woman. Psychology and \\ Behavioral Sciences. Vol. 7, No. 5, 2018, pp. 82-88. doi: 10.11648/j.pbs.20180705.11
}

Received: September 30, 2018; Accepted: October 9, 2018; Published: December 18, 2018

\begin{abstract}
Abortion refers to what is taboo and that affects the sacred, which consists in taking the life of a human being. And many women never or rarely speak about abortion. The Gabonese woman, generally resorts to the etiology of witchcraft to order to justify, on one hand, illegal abortion, often presented as an involuntary supernatural and malefic fact, when the latter is known to those around her and, on the other hand, to explain some secondary sterility that has resulted from unsafe abortions. The purpose of this work is to examine, in the case of Mufune, the archaic level of the psychic investment of the fetus or the embryo as an imaginary object in utero, articulated with the discourse of family persecution because of the difficulties inherent in reproduction for a woman. Abortion, even unsecured, thus refers to feelings and the lived experience of women all of which are part of a specific psychic space. The latter is born with the joint emergence of the desire to have a child, the desire of pregnancy and the desire for maternity which take shape at the moment when the question of the continuation or not of the pregnancy arises, and is instituted with the act of abortion together with all of the psychic effects.
\end{abstract}

Keywords: Psychopathology Gravido-puerperale, Psychic Space, Desire to Have a Child, Unsecured Abortion, Impossible Maternity, Imaginary Child, Gabonese Woman

\section{Introduction}

If several sources dating from the time of the Ancient Greeks and Romans (Ovid, Pythagoras, Plato, Aristotle, Hippocrates, Seneca, etc.), already evoked, without any ethical consideration, the question of abortion - including the associated risks - which doctors, philosophers and other thinkers of the time indicated by using the terms "losses" or "dissolution", far from being expressed or manifest, the psychic dimension, nevertheless, remains implied, suggested, and even latent. Anthropology would remind one that the studied human societies all practiced abortion in various forms [1], while admitting, paradoxically, the sacred nature of human life. Moreover, the prohibition of murder contained in the "Hippocratic Oath" and later, in religious philosophy and substantive law carries testimony thereupon.

Consequently, for most people in the world, abortion is taboo because it touches upon what is most sacred, taking life away from a human being. In fact, the violation of committing abortion still remains criminalized in many countries. "Before its legalization, voluntary abortion was regarded as a crime at the same level as voluntary manslaughter and murder" [1]. In other words, the act of abortion was regarded as the transgression of law, the violation of a taboo [2] and therefore, to transgress this prohibition, by crossing the prescribed limits, is done in secrecy and constitutes an act difficult to reveal in the history of the life of a woman. Most Gabonese women will never speak about it, and this is the basis of the etiology of witchcraft to justify, on one hand, the clandestine abortion, presented as if it were involuntary, supernatural and evil, when those around the woman are aware of the abortion; and in addition, to explain certain consecutive secondary sterilities accompanying unsafe abortions [3].

The context of life, lived experience, representations, legislation and sociocultural tolerance vary from one country to another and even from one individual to another. And rather than to have only one cross-cultural approach in dealing with this question of psychopathological interest, it is also wise to adopt an intercultural approach of the phenomenon of unsafe abortion, while questioning, inter alia, the effects of the culture on the issue. However, in the 
Gabonese cultural tradition, similar to other cultures on a continental and world scale, birth and death are regarded as the two extreme terminals of life so speaking about the taboo of abortion, supposes that the act itself concerns the social and religious prohibition to "kill", and thus transgress the prescribed limits. This act raises the idea of shame, which is the intention of requesting assistance in the non-therapeutic voluntary interruption, a fortiori, when it is practiced under unsafe conditions. From this point of view, what is the psychic investment of the fetus or embryo as an imaginary object in utero?

\section{Clinical Label}

\subsection{Presentation of the Mufune Case, 38 Year-Old Woman}

Mufune is a young 38-year-old woman, the third child of a phratry of five children including three girls and two boys, who all left the family home, each one living in his own home, married or single. The father, a retired male nurse raised them within the context of a quasi-martial education. The mother, also retired after a career as a school secretary is described as attentive, sweet, patient, discrete and affectionate. Mufune is a data processing specialist (expert in databases) in a private company. For the past fifteen years, she has lived with her 45-year-old partner - Diumbe, and she finds many qualities in him, unlike the negative attitude towards him on the part of her parents or her parents-in-law. One day she would love to marry him. However, up to the present, she is the only member of the phratry not to have a child.

\subsection{Reason for Consultation}

After a therapeutic course of about ten years, which led it to consult healers, marabouts, priests, pastors of waked up churches and gynecologists, via self-medication, it has been followed for three years by an obstetrician gynecologist, for infertility, after having diagnosed a secondary sterility. On the advices of this last, and following a depressive episode enough marked, accompanied by fit of tears, insomnia and feelings of family persecution, it comes in psychological consultation for, she says, "to leave the hole and to hope to be in peace".

\subsection{Clinical Data}

During various talks which we had with Mufune, her problems are summarized, in substance, with the feeling of family persecution resulting from her difficulty to have a baby with her partner, whereas all her brothers and sisters have at least two or three children, who are the joy of their grandparents and who often give them gifts, thereby frustrating and saddening Mufune during every family gettogether which Mufune was beginning to avoid. When speaking, often punctuated by sobs, Mufune would evoke her distress relative to her incapacity to procreate, whereas she had already been pregnant at the age of 26 when she underwent an unsafe abortion carried out by a neighborhood woman having nothing to do with the medical profession, but under the pressure of Ifutsi, her "first man", who gave her many gifts. He was single, about thirty years old, the father of two children at the time, and wanting to protect his imminent marriage with the mother of his children. Mufune said that this three-year adventure left her with deep wounds, a nightmare for her. She believes that her problems began there since her parents, including her brothers and sisters, did not want to hear about this relationship... She said, "It is as if they had withdrawn from my belly the possibility to have babies". As soon as Ifutsi knew that she was pregnant, he clearly meant not only to put an end to their relationship, with the insinuation that Mufune should have taken precautions not to get pregnant, and that he felt that he had been trapped by her since she knew that they were having relations during her period of fecundation, but he also said that he would not recognize the baby as his child. He said, "I shall not have a bastard in my family". Mufune felt that this regrettable abortion would always remain a black spot in her life: Unfortunately for her, the abortion destroyed her since a few months afterwards, Ifutsi left her, and in addition to the loss of the love of her life, she lost the capacity to have babies ever again through the secondary sterility provoked by the unsafe abortion. She said, "I could have had at least that baby in my life...".

In this report she seems to be crushed by a heavy feeling of guilt when she thought that all of her problems had started from there, because her parents, including her brothers and sisters, did not want to hear of this relationship, but she also felt guilty because of the inextinguishable desire to repair the fault, with her desperate attempt to become pregnant and to finally give birth to a child, this much desired child would again give her the hope of marrying Diumbe: "I hope God will bring on this long-desired miracle".

\section{Clinical Questioning Around Unsafe Abortion}

Is the difficulty in pregnancy leading to a live birth, or the consequences of a voluntary or involuntary act thereby ending the pregnancy, constitute a failure concerning the maternal function in itself? Does this failure automatically lead to the loss of self-esteem of a woman with no maternal function? Or at the level of the imaginary and symbolic system, the act of an abortion which consists in "killing an egg" that may represent a child to be born, from a psychopathological clinical, gravido-puerperal experience, is this likely to cause unhappiness, distress, guilt, anguish, regression, remorse and the regret to have 'killed' the baby, and thus to have transgressed the forbidden? If not, it would seem that the birth of a baby right after the abortion would likely help woman recuperate from this loss or help her surmount the deep wound of her self-esteem?

\subsection{Main Question}

If one looks more closely, there seems to be a paradox. 
The abortion as an answer to the question of the discomfort related to the desired or prohibited maternity, is in fact rejected in advance more so than as a reaction to being a mother or having a baby. And if the matter aims at finding an answer to the question, would the act of abortion be enough to remove the desire of pregnancy and/or having a baby, the phantasm of pregnancy and maternity, the feeling of guilt, the anguish of castration and loss of something valuable, generated by the risky abortion, leading to the impossibility of future maternity?

\subsection{Main Idea}

To begin with a negative answer, knowing that the probability for a woman to become pregnant, in spite of the precautions taken and that this pregnancy may end in an abortion, seems to defy logical rational, accrediting the thesis of Mr. Bidlowski who promotes the thesis of an "unconscious need" [4]. To follow through with this reasoning, it is less the prospect of having a baby, than the idea of going through a pregnancy that would lead to most abortions. All taken into account, the stakes of an abortion, could be considered on two levels: initially, the pregnancy itself which would remind one of the identification of one's own mother (the ideal of oneself); then, the abortion as it corresponds to the rejection of the baby, the refusal to give birth, which may allow one to imagine an unconscious hostility towards the mother.

However, with all these women wishing to have a child, it is above all desiring to give life again to the child they once were, and to some extent to replace their own mother [4]. However, one can admit that the eventuality of an abortion, or at least that which symbolizes the desire for an abortion, the act, the traces and the effects is that of the deadly mother child murder, reminding one of Cronos in Greek mythology, who ate her own children. But if the act of abortion of a pregnant woman is seen as a threshold going from femininity to maternity, envisioning the end to the pregnancy does not always exclude the attachment of the woman to the object of her pregnancy, the embryo or fetus, and maintains the phantasms of maternity and the child to be born, in utero.

In any case, confronted with family, social, cultural and economic contingencies, and more often in the case of despair, the woman deciding not to have a baby, whether it is desired or not, for which the woman is certain that she is neither psychologically nor economically, or culturally or even socially prepared to accept. It is therefore important for her not to be a mother of a child that the family and supposed father do not want, and that this would be a problem child, and so even an unsafe abortion will then be included in a specific psychic space.

\section{Psychic Space of an Unsafe Abortion}

The question here is to know, based on the traumatizing experience which constitutes an unsafe abortion, as related to the social, intercultural, family, religious, medical and economic environment, what the psychic space of the "unsafe" abortion represents for the Gabonese woman. It goes without saying that our assumption is based on the idea according to which, the psychic space of the "unsafe" abortion exists concomitantly with the sudden appearance of the desire to have a child, the desire for the pregnancy and the desire of maternity. It takes shape as from the moment when the difficulty of the continuation or not of the pregnancy arises, therefore of the decision to stop the process of pregnancy, and affirms itself through the act of abortion and the consequent effects of the abortion. Must one recall here that in this context of gravido-puerperality, the process of the maternal function as well as the desire to get rid of the pregnancy is a corollary to the refusal to give life or to have this baby?

However, such an event can only emerge from a conflict of ambivalence between, on one hand, the desire to continue the pregnancy with the narcissistic challenges, some of which concern psychic functioning [5] or the pleasure principle, and on the other hand, putting an end to it all, which is neither more nor less than the impulsive renunciation, corresponding to the other psychic functioning which is the principle of reality.

Thus, by admitting that it is taken in the throngs of a contrary and ambivalent desire, the woman in a gravidopuerperal situation, cannot imagine: "This child, I wanted it; I dreamed about having it. I was forced to remove it", which is the expression of a feeling of frustration while expressing her impotence faced with her partner. These remarks also reveal the difficulty of parting with the mourning of the aborted baby. In this sense, to continue or give up the pregnancy, under such conditions, generates not only the anguish of castration and guilt in both cases, but also causes trauma which can be related to the consequences of an impossible or risky pregnancy, difficult and painful to assume, without however occulting the violence of the act itself of unsafe abortion.

\subsection{From Abortion to the Birth of the Imaginary Child}

Nevertheless, in spite of the fact that it is a "still-born child", the fetus or embryo, object of the voluntary or involuntary abortion, therefore unaccomplished desire, will remain internally for the woman an "imaginary child" [6-10], without ever becoming a real child which, to a certain extent, shall constitute her own narcissistic prolongation. At first sight, the disowning of the pregnancy through an unsafe abortion shall have an impact on the disowning of herself in her maternal dimension and, consequently, a slight suicidal feeling of resignation and the loss of any hope: Mufune had said, "I have the feeling that my future is stopped, I have no future...". And as maternity emerges from femininity, there is no doubt that this disowning has an incidental impact on the image of the woman concerning the loss of her selfesteem. In this sense, one could say that the abortion clarifies in a certain way both maternity and femininity. It helps one to understand the challenges of maternity, in particular, its anguish, guilt, investment, disavowing and counter narcissistic stakes. Just as it gives meaning to the link between femininity and maternity, giving rise on the same 
occasion to the fantasme of the opposite of the "Virgin Mary", reincarnating and bringing on the suggestion of the "taboo of virginity" [11], although in this case, the woman is pregnant following a regularly risked sexual relationship, in her period of ovulation, with a doubtful partner. Nevertheless, the woman having gone through an unsafe abortion is between the idealization of the "imaginary child" and the phantasm of the 'killing' of the baby related to the violence of the act, on one hand, and the deep feeling of the resulting guilt for the loss of what could have been a child to be born.

Within the framework of the health of the reproduction of the African woman, and especially the precariousness of certain formal and abstract conditions which exist there, and in comparison with the distress of the woman (in the process of becoming a mother or potential mother), struggling against a problematic pregnancy, the abortion comes back to something related to psychic space which constitutes an intrapsychic conflict and its attempt to find a solution, thereby questioning as much the prohibited desire/of pregnancy in its narcissistic dimension since it represents a prohibited desire, or even an impossible maternity in reality.

This space is therefore to be found at the junction of the cause of the desire, the hatred then leading to the 'killing' of the imaginary object (the baby to be born), based on the anguish of castration: Mufune had said, "For me it was a nightmare"; followed, according to the approach of intercultural psychoanalytical psychopathology [12], by the feeling of persecution such as the substitute expression of guilt and anguish. She had added, "And I believe that my problems began from there, because my parents, including me brothers and sisters, did not want to hear about this relation... It is as if they had withdrawn from my belly the capacity to have a baby...") ; introjected identification ("I sometimes dream of a baby-ghost..."); a cleavage between the good and the bad baby ("The baby which cries but also smiles...") and projective identification accompanied by a feeling of persecution underlain by the anguish of castration ...("Tt was terrible. I had the feeling that par of myself was torn off...”). Such guilt, which assumes the omnipresent and torturing status of the abortionist, is understood as coming from the phantasmatic attacks of the woman against her object of love, which she fears in her fantasies since she is responsible for having destroyed it.

In this case, the guilt must be considered as allowing psychic elaboration, which consists of reappropriating the experience, subjectivizing it, the aim being to mitigate its traumatic impact. It can be understood as a way of treating trauma [13].

Not without evoking the forbidden desire to abort, especially since it is impossible to know beforehand the subtle link between a declared will and the desire that this will may conceal, knowing that the will can be unaware of the desire $[1,14]$. In any case, if according to psychoanalysis, the desire is by nature unconscious, it is important to recognize that the desire to have a child corresponds to the unconscious desire, which is therefore inextinguishable.

\subsection{Violence of the Abortion, Infanticide and the Anguish of Castration}

To be the act of violence, at the same time, in the field psychic, physical, cultural, social and legal, any abortion is to be registered in what we regard as spaces of intimacy [15, 16], heard here as the kaleidoscopic theatre supplied with primal phantasies in intra-uterine half-life which returns to the unfinished pregnancy, on one hand; of castration which represents the loss of part of oneself or the amputation of part of the body, in addition; of ending of the life of a baby which appears as the destruction of life. It is worth mentioning that the expression of an ambivalence, through the apparent contradictions, a sign of the intrapsychic conflict corresponding to the movements of love and hatred towards the unborn child, normally present in the mother $[17,18]$. This ambivalence would be materialized by the coexistence of the desire for a child (or childbirth) and the "infanticide desire" (Gallois, 2017). In this direction, the baby could thus represent the bad persecuting object that it would be good to annihilate [18].

Moreover, in connection with the primal phantasies, one can take a necessary development, regarding it as forming the unconscious, leading to the two entities; namely, the desire to have a child, fantasizing infanticide which are closely interrelated in the maternal mind [19], or in other words, the desire of pregnancy. Obviously, the act of abortion must be regarded as time in space, since it revives at the same time, not only the anguish of castration and castration itself which bring to mind the loss of the partial object following the abortion, but also and paradoxically, that of the feeling of persecution stated according to a method of cultural expression of guilt by means of projection of the destroying hatred of the internal object, however invested in the libido and certainly never disavowed.

With proof, the expression of persecution made on the day following the resulting medical complications of an unsafe abortion: as stated by Mufune, "and I believe that my problems began at that time since my parents, including my brothers and sisters, did not want to hear about this relationship. It is as if they had withdrawn children from me forever". As it is seen, the feeling of guilt remains difficult to assume and exteriorize by the patient, if not through her projection towards the outer world, thus allotting to others (father, mother, brothers and sisters, persecuting objects becoming able to remove from her any possibility of procreation , her own feelings of disavowing and guilt.

Consequently, the space wherein the child to be born results from the meeting of the desire or wish of life or death which underlies its intra-uterine life [20]. Thus the projection of the phantasms of devouring of the fetus is accompanied by a feeling of guilt, which also make it difficult to suppose an attitude of abstraction on the part of the abortionist as well as in the representation of the act of abortion as in the lived experience of the post-abortive phase characterized by mourning. 


\subsection{Masochism and Problems of Mourning}

This involves understanding the impulsive feelings of the woman in a situation of unsafe abortion and articulating it with a method of seldom explored psychic suffering, namely the psychic effects and experience of the abortion itself, of a woman having carried a pregnancy for a certain period of time, with the example of a precipitated birth, miscarriage happening quickly. Arises here the question of the psychic vacuum of the woman who has an abortion, of the prohibited desire/of a body (fetus) to remove from her own, the experience of a body partially emptied, or the emptying of another foreign body, in this case, a dead fetus before being born, who is no longer neither inside nor outside [10], with as a corollary, "the anguish of the emptiness" [21], distress regarded as primitive or archaic.

Because of its intensity and psychic effects, the unsafe abortion which becomes a loss of an object within the meaning of a violent expulsion of the object or disintegration of part of oneself (of one's body) can only be traumatizing for the woman, and thus generate depressive anguish and guilt. It is logical that the woman subjected to abortion should alternate between, on one hand, a depressive position [22], following the abortion marked by the destruction and loss of the child to be born, and on the other hand, the feeling of absolute power which allows this potential mother to remain a woman, to exert her right to give life or death, and in the case of abortion, death over the life of a baby.

It would appear that all of the psychical reality of the woman who has undergone an abortion is due to her capacity of be resilient, to overcome this narcissistic wound, and it is therefore necessary for her to restore to her psychic space of the unsafe abortion, the conscious and unconscious fantasizing of the woman for whom the act of an abortion becomes a sign of not being able to have a future pregnancy, but also the incapacity of being a mother. In This sense, Mufune reports the following : "I sometimes dream of a baby ghost". This can be seen as a regressive attempt to recreate the link with the lost object.

By referring to the figure of the baby-phantom that one can translate the term "ditengu di muane", in the Punu language, meaning the supernatural being, belonging from now on, to the world of the spirits $[12,23]$, she insinuates the presence of a being which no longer exists, in the form of a ghost expressing the desire thus to restore a link with someone who has been lost. Reduced to itself, this figure of desire is as close as possible to hollowness, the unnamable, absence, nothing, the lack and problem of loss and separation [24].

However, as an act of mutilation or better, of castration, the question of the body is not at rest. As such, abortion remains a violence to the body as well as a narcissistic loss. According to Mufune, "I had the feeling that a part of me had been torn off". Preceding this abortion, through seduction of a sexual object or, through response to the soliciting of a man, and at worst, based on rape, a woman can also be impregnated, which through the passage of weeks and months, is grows in her body and precedes the experience of maternity.

\subsection{From the Child Missing to the Impossible Maternity}

In all such cases of unsafe abortion, above and beyond the absolute power of the figure of the mother who has the power to give life or death, or the abortionist who also has the power to give death to a "living being", it is impossibility of assuming at the same time, this "child to be born", on one hand, but also its maternity to come or its improbable maternal function, on the other hand. Thus, based on the preceding, in the abortion, the words of desire coexist with those of the prohibited, those of love coexist with those of hatred. This ambivalence shall initially be based on the hatred of the object to reconstitute itself through the mechanisms of projection and the identification. It is especially the feeling of ambivalence with regard to the internal object (embryo or fetus) "killed" in the expelled maternal center and wherein the design is based on the libido of the other partner (through the desire of the child), with the hatred as well towards the fruit of this sexual act (the baby to be born) as against the author of the pregnancy or the impossible father.

In the same way, the act of abortion which has a traumatic effect can leave room to a masked or hidden mourning, and even sometimes undetectable, which is lived in silence, in the intimacy of the woman who has undergone an abortion. This kind of empty maternity narcissistically wounding due to the renouncing of the maternal function, is a result of the desire to have "killed" the "child to be born". With this analysis, in the act of abortion there would exist a double murder: one kills a "child to be born", the child whom the woman (who could not be made a mother through the birth of the baby) could have had, but will never have, on one hand, and the end of the mother (as in the case of secondary sterility), that which the woman could have become, the mother that the incipient child could have had. This leades us to mention a kind of absolute confusion between the other which represents the child, and oneself, or the mother [25].

\section{From the Termination of Pregnancy to the Non-transmission of Life}

In any event, with abortion, there is something which stops, which breaks the process of the transmission. There is a rupture in the intergenerational transmission chain, something unusual, so intimate to oneself which shall never be transmitted. Abortion is rupture. It is the rupture of filiation between that which could have produced motherhood (the maternal function) and that which could have created a new-born baby (the child of the mother) but also between that which could have been the father and his child, and finally, between the potential parents (the father and the mother).

All in all, let us say that the abortion brings together the figure of violence, fear, anguish, guilt, shame, negative thoughts, a stressful situation, the experience of a body 
suffering. Everything happens as if abortion refers here to "an act worthy of marriage" [18], namely, killing or aborting in order to survive, and the embryo or the foetus expelled at the time of an abortion will maintain the status of an imaginary object, and shall continue to resist its double implication as eal and symbolic. As in our voyage from birth to death, abortion tells of an"early" child murder based on the death instinct which is based on the anguish of death. There is, obviously, the oral desire of the mother (pregnant woman), as according to Chronos, to devour her "child".

\section{Burial of the Narcissistic Wound of the Abortion in Silence}

Extremely unfortunately, the effects induced by unsafe abortions among women can lead to secondary sterilities which accentuate the narcissistic wound and generate suffering and sometimes rejection on behalf of certain men, from the point of view of a marriage of which the goal would be to found a family as illustrated in the Mufune case. Under these conditions, felt as a vital threat to the patient, the pregnancy can lead to adopting any immediate solution to cope with the threat of the loss of the object of love and the fear of narcissistic collapse. But the silence which, most often accompanies this suffering, similar to the absence by any complaint relating thereto, cannot hide the psychic conflictuality to which it is subjugated, at the same time as it witnesses a certain psychic fragility which then requires a readaptation of psychic functioning which are based on the various elements of the specific context.

Therefore, if the act in itself, based on its frequency and numerous authors, can appear ordinary, because in our contemporary world, it is becoming common practice, although abortion is generally done in clandestinity, it is still true that the experience lived by women is far from being commonplace. The incurred risks and the consequences are often dramatic (death of the woman), traumatizing (haemorrhage, sterility and other complications), without medical assistance, involving major suffering although there are almost never voiced. One is confronted with a defensive act against a potential but impossible pregnancy, which is sealed in denial, narcissistic wound in the psychic space of the woman who has undergone an abortion, thereby echoing the silence of the act.

\section{Conclusion}

In conclusion, whatever the form or clinical experience, abortion cannot leave any clinician indifferent, nor nor any woman unscathed, on a psychic, corporal or social level, through the judgment of other people. Considered to be acts of violence, abortion remains a transgression of a fundamental prohibition, the effects of which are seen as psychic wounds. The psychic trauma undergone by Mufune who underwent an unsafe abortion, and who remains with a deep feeling of guilt, corresponding to the idea that she has taken life away from her baby, must be dealt with through psychological care.

It should be underlined that one should especially not lose sight of the dynamics underlying the act itself of abortion through the ambivalent phenomenon concerning the embryo or foetus, in the sense that this can lead to a conflict between love and hate, between the desire to promote life and the death instinct. The fact is that unsafe abortion, seen here as an extremely risky renunciation to maternity, brings with it the end of a completed pregnancy, the non-birth of a newborn and an effective maternity which may find its biological results in secondary sterility, thereby complicating the mourning period. In summary, the psychic space of unsafe abortion cannot be established outside of what should be called "the subjective experience of femininity and motherhood", insofar as pregnancy is reflected as one of the markers of female identity, which testifies to the weight of social norms in the definition of the feminine [26].

One should all the same point out the fact that if the gravido-puerperal situation is likely to cause unhappiness, distress, anguish, guilt, regression and remorse of a woman who has had an abortion, it goes without saying that among the causes of consecutive secondary sterility after unsafe abortion, mentioned by Mufune, one finds in her first lines, the feeling of persecution, culturally codified [27, 28]. In this sense, the misfortune of Mufune may have been based on her family who never hid their opposition to her relations with Ifutsi, thereby justifying her belief that she was a victim of bad fate or, more concretely, of a family curse, in reprisals with her stubbornness to continue her relationship, considered by her family to be doubtful and adventurous.

In this context, the feeling of persecution appears to be individually appropriated based on the intercultural reality wherein her feelings of guilt and anguish [12], and her defence against those feelings of guilt and anguish, that is, her guilty conscience and to clear her fault (in particular, concerning the act of abortion, which has now deprived her of any future maternity), based on refusing to take on the responsibility for the act, she has placed it outside of herself through the process of projection.

\section{References}

[1] J. Dayan \& al. (2003). «Psychopathology of Perinatality». Paris, Masson.

[2] S. Freud (1913). Totem and Taboo. Interpretation by Psychoanalysis of the Social Life of Primitives. Paris, Payot, 1989.

[3] I. U. Moundaka (2014). Obstacles to access to Emergency Care following the Complications of Unsafe Abortions in the Middle Ogooué, Province of Gabon: Legal, Sociocultural and Medical Aspects, New Regime Doctoral Thesis in Psychosociology, University of Paris 8 -Vincennes Saint-Denis.

[4] M. Bidlowsky (1980). To desire a Child or to give Birth to a Desire. F. Charvet (éd.), Desire for a Child, Refusal of a Child. Paris, Stock. 
[5] S. Freud S (1911). Formulations on the Two Principles of PsychicFfunctioning. Results, Ideas, Problems, Paris, PUF, 2011, pp.135-143.

[6] M. Soulé (1983). The Child in the Head, the Imaginary Child. The Dynamics of the Baby or What's New Baby ? ( pp. 137175), T. B. Brazelton, B. Cramer, L. Kreisler, R. Schappi, M. Soulé, (éds), Paris, E. S. F.

[7] R. Doron \& F. Parot (2011). Psychology Dictionary. Paris, PUF.

[8] S. Lebovici. (1989). «Intergenerational Links (Transmission, Conflicts). Phantasmatic Interactions ". Psychopathology of the Baby, Paris, PUF, pp.141-146.

[9] C. Stein (1991). The Imaginary Child. Paris, Denoël.

[10] M. J. Soubieux, F. Daffos, S. Missonnier, M. Soulé (2013). The Empty Cradle: Perinatal Mourning and the Work of the Psychoanalyst, Toulouse, Erès.

[11] S. Freud. (1917-1918). The Taboo of Virginity. Sexual Life, Paris, PUF, 1977, pp.68-80.

[12] S. Mbadinga (1994). The Psychopathologies of Persecution in a Gabonese Population - theTheme of the "Ghost" - Dynamics and Dialectics of Culture and Psychopathology, New Regime Doctoral Thesis in Clinical Psychopathology, Université of Nice Sophia-Antipolis, France.

[13] A. Ravier, D. Scotto Di Vettimo (2017). Psychopathological Approoach of Premature Child : the Maternal Guilt to tend to/ to attend the Link to the Child. Mediterranean Clinics Psychoanalysis and Freudian Psychopathology, 96, 245-256.

[14] M. M. Chatel (1993). Malaise in Procreation. Women and Childbirth Medicine. Paris : Albin Michel.

[15] F. Bégoin-Guignard (1987). At the Dawn of the Maternal and the Feminine. Essay on two Concepts as Obvious as Inconceivable. French. Review of Psychoanalysis, 51, (6), 1491-1503.

[16] F. Guignard (1995). The Maternal and the Feminine: two Spaces of Psychic Life. Clinical and Projective Psychology, 1, (1), 7-26.
[17] D. W. Winnicott. (1947). Hate in the Counter-Transference. Through Peadiatrics To Psycho-Analysis, Paris, Payot, 1969, P. $72-82$.

[18] A.. Gallois (2017). The Infanticide Desire, a Common Paradigm of the Material Conflict. Mediterranean Clinics. Psychoanalysis and Freudian Psychopathology, 96, 257-266.

[19] D. Bastien. (2011). « I killed my Child ..». To Think about the Abortion Clinic. Clinical Psychology Papers, 2, (37), 149-163.

[20] J. Clerget (1986). Fantasies and Masks of Pregnancy. Lyon, P. U. L.

[21] C. Chabert (2007). The Forbidden Touch and the Paradoxical Transfer. The PSY Notebook, 4, (19), 24-28.

[22] M. Klein (1934). Contribution to the Study of the Psychogenesis of Manic-Depressive States. Psychoanalysis Essays, Paris, Payot, 1968.

[23] W. Raponda, R. Sillans (1962). Rites and Beliefs of the People of Gabon. Essay on Past and Present Practices. Paris, African Presence

[24] S. Mbadinga (1999). The "Cultural Icon" or the Logic of the Truth of Desire. Psychology and Culture, 1, (1-2), 20-25.

[25] M. Benhaïm (2002). Maternal Guilt. The Letter of Childhood and Adolescence, 1, (47), 49-56.

[26] S. Mbadinga, G. Ngabolo, M. Mboussou. (2002). To care in Circle. On the Front of the Sharing of Therapeutic Space in Black Africa. Mental Health, Psychotherapy and Culture. The World Council for Psychotherapy, Vienna, 2002, pp. 89-98.

[27] S. Mbadinga. (2003). "The Situs Analysis " and the Traditional Therapeutic Framework in Africa. Psychiatry, Psychoanalysis, Culture., R. Collignon \& M. Gueye (eds). Society of Psychopathology and Mental Hygiene, Dakar, pp. 417-431.

[28] V. Simoglou, D. Garnault (2017). Pregnancies in Times Biomedicalization: «Loans» from another Womans'Body.. Mediterranean Clinics. Psychoanalysis and Freudian Psychopathology, 96, 37-49. 